\title{
Teachers' experiences of teaching Accounting in the context of curriculum changes in South Africa
}

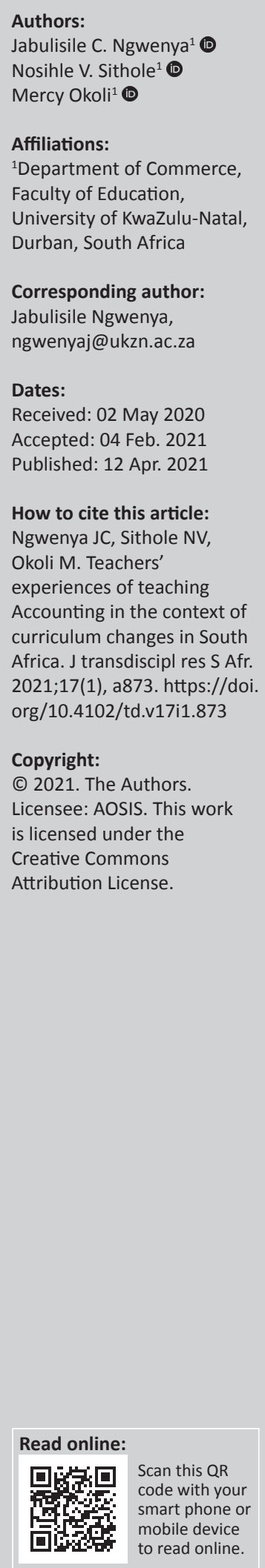

Accounting as a subject is plagued by persistent changes because of shifts in the discipline originating from the developments in the profession. This study focuses on teachers' experiences of teaching Accounting as a subject during the time of curriculum change. It adopts an interpretive qualitative case study design to get a thorough understanding of Accounting teachers' experiences. Data were obtained through reflective journals and semistructured interviews from five purposively selected Accounting teachers. The results of the findings indicated that Accounting teachers often struggle to teach new content as learners lacked adequate background knowledge needed to learn Accounting in succeeding grades. The unique language of the subject, shortage of textbooks and insufficient assessment activities in the textbooks constrained the teaching of Accounting. In addition, school management and Accounting specialists were found wanting in terms of the support offered to teachers as well as and providing regular advisory services to them because of insufficient knowledge of the subject and inadequate supervision skills. The study recommended that heads of departments should be fully trained on curriculum changes in their subjects to be able to provide guidance and supervise teachers under their leadership. On-going support should be provided by the subject advisors in schools to assist teachers with challenging topics and teaching strategies.

Keywords: accounting; accounting teachers; curriculum changes; language of accounting; teachers' experiences; teaching of accounting; teaching resources.

\section{Introduction}

The South African educational landscape has gone through a number of changes over the past two decades. It is worth noting that the introduction of the National Curriculum Statement (NCS) in 2006 and the Curriculum and Assessment Policy Statement (CAPS) in 2014 in the Further Education and Training (FET) band resulted in redesign and the reconceptualisation of all subjects offered in the FET phase. Curriculum changes were necessary to foster the skills needed for a democratic society and the globalised world. ${ }^{1,2}$ The changes that were reflected in Accounting as a school subject were intended to better align it with the international Accounting standards in the Accounting profession. ${ }^{3,4}$ As such, it altered the misconception teachers and learners had whereby they regard Accounting accounting as a routine subject that is only centred on the process of bookkeeping and recording of transactions. ${ }^{5,6}$ Another major change in Accounting was the introduction of new topics which gave rise to a shift in the prescribed subject content and the movement of topics within the grade and across the grades. ${ }^{7}$ Addition of new content resulted in expanded breadth and depth in the Accounting curriculum. Consequently, Accounting is now inclined towards cognitive levels which require description and understanding of the relationship between concepts as well as complex reasoning. ${ }^{6,7,8,9}$ Myers $^{4}$ notes that these changes and subsequent restructuring in the Accounting curriculum have had serious implications in terms of adjustment of teaching, learning and assessment.

Makunja ${ }^{10}$ argues that whilst implementation of the change in curriculum has to be resourceintensive to succeed, the teacher remains the key driver of a successful curriculum transformation. In line with this view, Okoth ${ }^{11}$ advocates that failure to align teacher-training methods to the needs of teachers can restrict the development of their content knowledge. This failure may lead to unsuccessful implementation of curriculum reforms by the teachers, which is then attributed to their poor conceptual understanding of reforms in their specific subjects. ${ }^{1,11,12,13}$ Whilst teachers do undergo training to keep abreast of new developments in education, the extent to which training prepares them is questionable. This is particularly the case in Accounting where teachers were expected to change to a conceptual approach in teaching of content knowledge. With research indicating teachers' difficulties in implementing the curriculum changes ${ }^{1,10,14,15}$ and students' high 
failure rates, conducting a study that focuses on teachers' experience of teaching in the context of the curriculum changes is clearly important.

Furthermore, research has shown that ever since the implementation of the CAPS in the FET phase in South Africa, very little research has been embarked on in Accounting. ${ }^{6,8,9}$ This paucity makes the findings reported in this article particularly notable as it adds to knowledge in the current research in Accounting Education, predominantly regarding teachers' experiences of teaching the subject in the context of the curriculum change. The question that guides the research is as follows: What are the teachers' experiences of teaching Grade 12 Accounting in the context of curriculum changes in South Africa?

\section{Literature review}

\section{Teachers' experiences of implementing curriculum changes}

Research has shown that effective implementation of a curriculum in schools hinges on school-based condition. . $11,12,13,16$ Almost all the authors mentioned previously emphasise that most hindrances in the effective implementation of the new curriculum are found within the schools. Makunja ${ }^{10}$ and Okoth $^{11}$ highlight the fact that insufficient teaching and learning materials to support the implementation is a major challenge to curriculum implementation. Textbooks offer teachers structured and thorough presentation of the subject matter. However, numerous studies have found that teachers were not provided with enough textbooks. ${ }^{10,11,12}$

Shilling ${ }^{12}$ points out that teachers' lack of adequate content knowledge is one of the main hindrances to the effective delivery of a curriculum. This calls for necessary teacher development because successful implementation of any curriculum is reliant on the teachers' potential to translate the written curriculum into classroom learning experiences. However, lack of teachers' professional development has been identified in literature as one of the obstacles to curriculum implementation. ${ }^{12,13,17}$ As the curriculum changes and implementation affect teachers in significant ways, training the teachers who are expected to make the curriculum a classroom reality is of utmost importance.

If relevant support is not provided to teachers to cope with the additional demands because of changes in content, the execution process will be ineffective. Makunja ${ }^{10}$ regards frequent supervision of teachers as one means of monitoring implementation of the curriculum. Makunja adds that it is the obligation of the heads of departments and head teachers to supervise curriculum implementation. However, research suggests that because of incompetent school leadership and management, there is often a failure to offer sufficient support and monitoring of actual execution of curriculum changes in the classroom..$^{10,12,13,17}$

\section{Teaching of Accounting}

Research in Accounting Education ${ }^{3,4,5,18}$ highlights that changes in the Accounting curriculum required teachers to modify their teaching and assessment methods to align them with the demands of the new curriculum. The assumption was that the adoption of diverse teaching approaches could lead to advancement of accounting proficiencies that are required in order to succeed in the profession. This is confirmed by Thomson and Washington,, ${ }^{16}$ who found that using alternative teaching strategies encouraged the development of the critical thinking skills learners need in solving financial problems. However, with regards to assessment, Ngwenya and Maistry ${ }^{27}$ that there are problems with teachers' understandings and interpretations of assessment in schools. Accounting is a discipline that requires more practice than most others because of its practical nature..$^{3,5,16,18}$ Erasmus and Fourie ${ }^{18}$ advise that a range of assessment tasks should be given to learners to involve them in discussion whilst encouraging them to think creatively. This means that in Accounting, assessment activities must cover the entire content of the subject as well as the variety of skills that cover a range of cognitive levels to cater to different learner abilities.

However, research has revealed that formative assessment is not understood by teachers because of a lack of conceptual understanding of Accounting., 5, 18,27 This has an impact on effectively teaching it. The situation is worse in rural schools where teachers are faced with the challenges of large classes and a shortage of resources, especially textbooks. Because of this, many learners attain poor outcomes. Whilst in Accounting, learners are confronted with scenarios that entail multiple and different solutions, providing feedback was found to be challenging as learners struggled to formulate solutions because of language impediment. ${ }^{6}$ In addition, it was difficult for teachers to write diverse lengthy comments when providing feedback to large classes in rural schools. Teaching and assessment in Accounting requires understanding and using a variety of teaching and assessment strategies.

\section{Theoretical framework}

This study was framed with the curriculum implementation theory developed by Rogan and Grayson. ${ }^{19}$ The theory involves profile of implementation, capacity to support innovation and support from outside agencies as its three main concepts.

The profile of implementation permits one to recognise the degree to which the new curriculum is executed in the classroom. ${ }^{19}$ According to Rogan and Grayson, ${ }^{19}$ factors to consider during a curriculum change include knowledge of how to execute change, learners' prior knowledge, language use and classroom interaction. Capacity to support innovation recognises how the school context can support or hinder curriculum implementation in terms of physical resources, school ethos and management, teacher factors and learner 
factors. ${ }^{19}$ Fullan ${ }^{20}$ argues that access to physical resources is essential because inadequate resources can inhibit the ability of the teachers and learners to successfully implement the curriculum.

According to Rogan and Grayson, ${ }^{19}$ outside agencies interact with a school to provide external support with the aim of facilitating curriculum implementation. These outside agencies could be government departments, NGOs and unions that may provide material and non-material support and monitoring on the curriculum changes in the school context. In this study, external support will focus on nonmaterial support offered through professional development. This kind of support is crucial in supporting and monitoring the recurring implementation changes in Accounting.

\section{Research methodology and design}

The interpretivist paradigm using a qualitative case study strategy was adopted in the study, as we were interested in understanding the experiences of Accounting teachers in teaching Grade 12. The choice of the interpretivist paradigm is based on our belief that there are multiple, socially constructed realities, which affect our decisions regarding the interpretation of data. ${ }^{21,22}$ As the aim was to obtain a thorough understanding of Accounting teachers' experiences, adopting a qualitative case study design was deemed suitable. ${ }^{23}$ In accordance with the main assumption of the case study, in this study the bounded system ${ }^{23}$ was a group of five Accounting teachers.

The choice of schools was based on the accessibility of the participants to us as researchers as well as their willingness to participate in the study. This necessitated confining the study to neighbouring schools where we work. Therefore, five schools in Umlazi South district were chosen as they were easily accessible and willing to participate. ${ }^{24}$ Five Accounting teachers who were teaching Accounting in Grade 12 were handpicked (one teacher per school) as they shared common characteristics. ${ }^{21}$ The number of participants is supported by Farrugia, ${ }^{22}$ who argued that in qualitative sampling the researcher selects a small number of participants who will provide in-depth information about a given phenomenon under study.

Semi-structured one-on-one interviews were conducted to probe the Accounting teachers' experiences of teaching Accounting in Grade 12. Interviews that lasted approximately 45 min each were conducted at the participants' workplace during their free periods. Prompts were used to ensure uninterrupted conversation. In addition, the interviews were tape-recorded after obtaining the assent of each individual participant. Recorded interviews were transcribed verbatim to ensure that the participants' views were captured correctly during transcribing. Participants' experiences of teaching Accounting in Grade 12 were supplemented through teacher reflective journals. Also, the use of teacher reflective journals allowed us to capture information that may have been omitted in the interviews; in that way, relevant information was gathered. Teachers were asked to write their experiences of implementing Accounting changes in their personal journals.

Thematic analyses were utilised to analyse the data obtained from face-to-face interviews and reflective journals. ${ }^{21}$ The data analysis process began by transcribing face-to-face interviews to textual data. The transcripts were then read several times to identify units of meaning, in order to access the deeper meaning of the responses received. The categories were established by means of open coding. Categories were then revised and grouped into specific themes to report the findings. Themes that developed from the interviews were employed to analyse reflective journals.

\section{Findings}

The findings will be reported through the following two themes: factors influencing implementation in the classroom and capacity and support to implement a new curriculum. Verbatim quotes are used to capture participants' experiences.

\section{Factors influencing implementation in the classroom}

Teachers found that learners' background knowledge or preparedness, instructional language and unique language of Accounting and assessment in Accounting were found to be the main factors that hampered the implementation of changes in the Accounting curriculum.

\section{Learners' background knowledge in Accounting}

Prior knowledge and perceptions that learners arrive with in the classroom form the foundation for new knowledge they construct. In Accounting, learners' background knowledge is crucial as each topic builds on the previous knowledge. Findings showed that teachers were worried that learners had not acquired adequate background knowledge in previous grades as they lacked understanding of the basic Accounting principles. Brian further explained that lack of background knowledge might be because of the way the Financial Literacy content is structured in Grades 8 and 9. The topics are not taught consecutively: 'In Economic and Management Sciences (EMS) there are three components and Financial Literacy topics are scattered and not taught in one term'.

Teachers mentioned that the Accounting content in Grade 9 is too simple to give learners the relevant skills they need for further learning in the subject. As a result, they get inadequate exposure to knowledge and skills they are expected to acquire before they get into the FET phase. Zuzeka added that when learners got to Grade 10, they lacked sufficient understanding of foundational concepts and principles that were pertinent in learning Accounting in the subsequent grades:

'What I have seen in all the years of teaching Accounting in the FET phase, when learners get in to Grade 10 they can name 
Accounting terms but they do not understand, they just memorise theme and this affects their learning in Grade 11 and 12.' (Zuzeka, FET Accounting teacher, 22 March 2019)

In Accounting, students learn better when they build on preceding knowledge, which helps them reinforce the connections between present knowledge and the new concepts about to be learnt. Teachers concur that because many learners come to Grade 12 with limited previous knowledge, textbooks should give them the full background knowledge needed to learn Grade 12 content. However, teachers raised concerns about the information found in textbooks with respect to previous knowledge that a learner is required to possess prior to learning the new topic. Teachers' responses revealed that textbooks fell short in providing support regarding previous knowledge:

'Our learners are not well-prepared, even though they face the challenge of forgetting. Especially in new topics there is nothing in the textbook that reminds me about previous knowledge of learners. I use my experience.' (Zama, FET Accounting teacher, 22 March 2019)

\section{Language of instruction and the unique language of Accounting}

Teachers experienced language as one of the serious impediments in the teaching of Accounting in Grade 12. Teachers explained that learners who were not fluent in the language of instruction often found it difficult to comprehend the new concepts. Although the language of teaching hindered effective learning of Accounting, teachers believed that the unique language of the subject intensified the challenges. This had major consequences for the teaching and learning of the subject. Teachers mentioned that the language of Accounting is unfamiliar to learners, and terminology encountered in the subject is difficult to master and comprehend. This is confirmed by Senzo who added that because Accounting is a subject with its own distinctive language, learners often fail to understand new knowledge as they find it difficult to make sense of the unique concepts of the subject. The situation is worsened when the language of teaching Accounting is the learners' second language:

'You know language is the reason why my learners fail Accounting because in Grade 12 or any other Grade, Accounting has its own vocabulary which learners must get used to. If they do not understand simple English it becomes difficult to understand the subject.' (Senzo, FET Accounting teacher, 25 March 2019)

Teachers said the language barrier added to learners' challenges in solving financial problems. Zama noted that learners often could not analyse financial information because of an inadequate understanding of the language of Accounting. Learners frequently struggle to provide sound solutions to the financial problems. Although they understand the information provided, they often find it challenging to formulate responses because of linguistic limitations in communicating in English: 'In most cases they find it difficult to answer questions in tests. It is difficult to come up with the answers in English' (Zama, FET Accounting teacher, 22 March 2019).
Teachers were of the opinion that it was their responsibility to explain the text in the mother tongue first and then revert to English in an attempt to clarify new concepts and to assist learners in understanding the task requirements. Teachers believed they were compelled to use the learners' home language to facilitate the learning of Accounting. Therefore, they make use of code switching in teaching Accounting to overcome the challenge and to encourage learning. This is what Beauty (FET Accounting teacher, 01 April 2019) said: 'I always code switch. It helps a lot especially when I'm introducing new topics. I always explain each word on the topic in English and IsiZulu'.

Furthermore, teachers were concerned that learners were often passive in the classroom and rarely engaged in meaningful discussions as they were required to respond in English. However, teachers found group discussions to be a learning space that provided support in allowing learners to share their ideas and thoughts freely within their groups using their home language.

Teachers raised concerns that although the use of code switching helped in clarifying new concepts, other Accounting concepts could not be explained in IsiZulu. There were words that did not have an equivalent in the learners' mother tongue because they originated from another language apart from English. As a result, teachers had to use visuals like pictures to illustrate the new concepts. Whilst visuals were believed to be of great help in enhancing the learning of new and unfamiliar concepts, teachers raised concerns that pictures that were meant to enrich learning of new concepts were hazy in the textbooks they were using. Furthermore, teachers expressed their discontent that schools do not have funds to buy Accounting posters that are pertinent in illuminating unfamiliar concepts:

'In the books, there are pictures and other graphics to emphasise new concepts and help learners understand. But they are in black and white and they are not clear. Posters are better.' (Zuzeka, FET Accounting teacher, 22 March 2019)

'We raised the issue of putting up posters with terms and pictures, but the principal said there is no money.' (Senzo, FET Accounting teacher, 25 March 2019)

Sometimes teachers are compelled to use the learners' home language to facilitate the learning of Accounting as the language of instruction was a barrier to learning. As a result, teachers on many occasions had to switch to the mother tongue for further explanation of new concepts. In addition, they used the learners' everyday experiences and immediate environment to clarify new knowledge.

\section{Assessment in Accounting}

Accounting teachers explained that the practical nature of the subject requires learners to undertake repeated and frequent written activities and tutorial exercises. These help teachers to consolidate the learning of new knowledge and check the learners' level of understanding. In Accounting, different forms of assessment should be used to allow students to practice what they have learnt. However, teachers 
raised concerns that teaching and assessment of new knowledge was a challenge because there were insufficient activities in the textbooks to allow students to review what had been learnt in class:

'We normally encounter problems when teaching new topics. There are fewer activities in the textbooks to practise.' (Senzo, FET Accounting teacher, 25 March 2019)

Whilst it is imperative for learners to be equipped with critical skills in class to prepare them for examinations, teachers were perturbed by the shortage of problem-solving activities in the textbooks. Teachers indicated that there were too few activities that allowed learners to evaluative financial information and show creative cognitive thinking. On the same issue, Zama (FET Accounting teacher, 27 March 2019) highlighted that activities found in the textbooks were mostly on the lower- and middle-order cognitive level as they require learners to apply procedural knowledge: 'I always have a problem when I want to give my learners more work in problem solving. The activities are not challenging learners. They are very easy'.

Whilst examination papers cover all cognitive levels, teachers were worried that activities found in their textbooks did not match the standard of questions in the National Senior Certificate examination papers in terms of the level of challenge. This challenges learners when they are writing examinations because they are not sufficiently equipped to answer the higher order questions:

'Evaluation and creativity are not covered adequately. There are no higher-order activities to help teachers to prepare learners for the examinations.' (Beauty, FET Accounting teacher, 01 April 2019)

Teachers felt that the level of challenge of the activities given in class failed to prepare learners for examinations. Teachers therefore use past examination papers and the examination guideline.

\section{Capacity and support within the school}

Accounting teachers expressed their views on how physical resources and support from school management and learners hampered or supported the implementation of curriculum changes in school.

\section{Physical resources}

Teachers regarded textbooks as the main resource they needed to support the implementation of the CAPS Accounting curriculum. They further explained that when the new curriculum was implemented in 2014, enough textbooks were ordered for the number of learners who were in Grade 12 in that specific year. However, teachers mentioned that there was a shortage of textbooks because of the increased number of learners:

'Because there are more learners in my class than the previous years, other learners do not have textbooks.' (Zuzeka, FET Accounting teacher, 22 March 2019)

Beauty confirmed that when textbooks were lost or when the number of learners increased, textbooks were not replaced and, as a result, there were not enough for all the learners in class.

Teachers felt that understanding accounting concepts depended on the information found in the textbooks. What is remarkable though is that prescribed textbooks do not provide a detailed explanation of the unique concepts. Teachers mentioned that they encountered problems when preparing lessons, especially for new topics, because they do not have enough teachers' textbooks to consult to get different perspectives on the topic. Teachers indicated that other textbooks did not have sufficient content, and as a result, they found it problematic to prepare lessons:

'Textbooks should give us more knowledge about new accounting terminology when doing lesson plans. Definitions are there but do not give full information; [for example] the buyback of shares is not explained clearly.' (Beauty, FET Accounting teacher, 01 April 2019)

This shortcoming compelled Senzo (FET Accounting teacher, 25 March 2019) to use more than one textbook to teach new concepts. It is however unfortunate that he had to buy other Accounting textbooks using his own funds because the school could not afford to buy additional textbooks: 'I bought two books because they explain new terms clearly but I do not have a teacher's guide. The school does not have money to buy them'.

Teachers expressed concerns about the coverage of content within the main topics. They indicated that whilst the new topics appeared in the textbooks, information provided was not comprehensive enough for learners to understand the topic. In addition, textbooks do not provide teachers with sufficient content to explain the topics thoroughly in class.

\section{School management}

In this study, all teachers were Accounting specialists with adequate qualifications. Although teachers were well equipped and had relevant expertise to teach Accounting, they were concerned about major changes in the CAPS Accounting curriculum. Teachers mentioned that the introduction of new topics was seen as a huge change in Accounting. Although they had been teaching some new topics, they were still not confident to teach others. Teachers added that Accounting is not about calculations anymore; it requires understanding of theory to be able to analyse financial information and to solve financial problems. They often found it challenging to equip learners with the analytical skills needed to analyse financial information. Their main concern was that they often did not get adequate support from the school management:

'There are different topics that have been added: Buying back of shares and calculation of average price. There is more theory and learners have to understand it. If I ask my HoD, she does not know these new topics.' (Brian, FET Accounting teacher, 30 March 2019) 
Beauty (FET Accounting teacher, 01 April 2019) added that other new topics were not easy to introduce; she does not get enough support from management. The situation is exacerbated by the fact that the Commerce Head of Department (HoD) was not an Accounting specialist: 'My HoD does not help me much; she did not know much about Accounting, she majored in Business Studies'.

Because teachers do not get the support they need from management, they rely on other Accounting teachers in the cluster:

'I get help from the cluster coordinator, who is very good in Accounting.' (Zuzeka, FET Accounting teacher, 22 February 2019)

Zama said her HoD had limited understanding of the changes in the Grade 12 curriculum, as he was not teaching that grade:

'My HoD never supported me with the challenges I had in CAPS Accounting content; instead, he gave me permission to consult cluster colleagues.' (Zama, FET Accounting teacher, 27 March 2019)

The fact that teachers got insufficient support from their heads of department was concerning. They indicated that their principals were very supportive even though some did not fully understand the curriculum being implemented.

\section{Learners' parental support}

Whilst parental involvement in learners' learning is of paramount importance, teachers were concerned that parents did not support their learners. Learners from certain backgrounds were less likely to get sufficient support. Teachers mentioned that most learners do not get the necessary guidance and support in the completion of school tasks because they come from grandparent-headed and child-headed families. A number of learners were grappling with multiple and competing responsibilities as they were also expected to take up parenting responsibilities and household duties. This is what teachers said:

'In my class there are children who live with their grannies. They are old and they do not come to school when you call them.' (Zama, FET Accounting teacher, 27 March 2019)

'Our learners do not have time to do homework because when they come back from school they have to cook, and do washing for other children and some have no parents to support them.' (Zuzeka, FET Accounting teacher, 22 March 2019)

Teachers added that some learners normally do not do homework because of problems emanating from their home context. Teachers commented that they do not receive support from many of the parents in successful implementation of curriculum changes. Some of the children, when they get home, are required to take up family responsibilities and daily errands. As a result, they do not have enough time to focus on their schoolwork.

\section{Capacity and support from outside the school}

Teachers regarded in-service training offered by the Department of Basic Education (DBE) as the main factor affecting support received outside the school.

\section{Professional development}

All five teachers agreed that they had received training on the changes in Accounting, but said it was not enough. They were concerned also about the time allocated for the workshops, saying it was insufficient to grasp all the information on new content. They had this to say:

'Yes, I did get some training ... it helped me because I was officially informed about these curriculum changes in Accounting but the time was not enough.' (Senzo, FET Accounting teacher, 25 March 2019)

'For me there was little time to unfold every change that took place. I had to train myself on some topics, so that was a challenge for us.' (Zama, FET Accounting teacher, 27 March 2019)

Senzo was discontented over the way the workshops were conducted. He stated that those who were conducting workshops seemed not to be adequately knowledgeable. He added that the workshops were not practical enough to help teachers with classroom implementation:

'Subject advisors were mostly telling us about changes in the Accounting curriculum. Practical examples were not given. I met with other teachers. We discussed all our problems and they gave me methods of explaining the new concepts.' (Senzo, FET Accounting teacher, 25 March 2019)

Senzo was not satisfied with the workshop, and saw workshops primarily as a space for advanced networking. He commented that the space provided him the opportunity to discuss his challenges with other Grade 12 teachers. This assisted him in developing classroom strategies to handle difficult concepts.

Teachers were of the impression that after attending workshops, consistent monitoring should have been provided to support them with implementation. They expressed concerns that the DBE did not offer constant monitoring. Zama added that there had never been school visits by the subject specialists to attend to individual teacher's challenges with the implementation, especially as there were continuous changes in Accounting: 'In my district, monitoring never took place; subject advisors were coming to school if there has been a request or if a school is failing'.

Teachers were only invited to attend workshops informing them about the dates for common examinations and the review of the past year's results at the beginning of the year. They normally saw the workshop space as an opportunity to share information about different Accounting topics and how to teach them creatively.

\section{Discussion}

The purpose of the study was to explore teachers' experiences of teaching Grade 12 Accounting in the context of curriculum changes in Umlazi South district in South Africa.

According to Ajani, ${ }^{25}$ if students don't have sufficient related knowledge, they are likely to have difficulties in 
understanding new content. Therefore, he underscores the importance of background knowledge in learning new knowledge. According to this study's findings, Accounting teachers found that that inadequate learners' background knowledge contributed to a delay in the successful implementation of the subject in the classroom.

For Accounting learners to grasp key financial transaction, as well as analysis, interpretation and communication of financial statements, they must understand Accounting language and fundamental concepts of principles and practice. ${ }^{26}$ Language was pronounced a main hindrance in teaching Accounting, as Grade 12 learners failed to understand financial information and were unable to make sound decisions. Findings revealed that for second language speakers of English, the type of scenarios and the unique language of accounting impeded the effectiveness of teaching and learning in this subject. Learners were normally scared to talk in class because their command of English as the medium of instruction was not good enough. The teachers' views and experiences are consistent with Myers, ${ }^{4}$ who found that students had to first translate Accounting concepts into English and then translate them into unique meanings in the Accounting world. To accommodate learners, teachers had to use group discussions as a strategy to encourage them to share their ideas and thoughts. This created a learning space that provided support in allowing learners to express their views freely within their groups using their home language.

In KwaZulu-Natal, schools are allocated funds to purchase one prescribed textbook for each learner. Because of a shortage of funds to buy more books for teachers, most teachers rely on this prescribed textbook to teach. Makunja ${ }^{10}$ regards textbooks as one of the teaching and learning resources whose availability can sustain the implementation of a curriculum. However, the teachers reviewed in this study experienced a shortage of textbooks and this hindered effective implementation of changes in Accounting, as they were viewed as essential teaching and learning material. In addition, teachers found textbooks wanting in helping them with sufficient information required to teach the new content.

Findings revealed that support from parents was lacking in various home conditions. Whilst the subject required learners to do practice activities at home, teachers had the challenge of learners not doing their homework.

Teachers reported that heads of departments did not provide sufficient and effective support they required owing to insufficient subject knowledge and inadequate supervision skills. This is in line with Sabola ${ }^{17}$ who found that it was difficult for heads of departments to provide supervision on a subject they did not specialise in. Sabola's finding is confirmed in this study as Commerce HoDs were not confident enough to offer advisory support to the Accounting teachers because they did not understand the new content. The situation was aggravated by the fact that some of the Commerce HoDs were not Accounting specialists.
Teachers confirmed that a lack of thorough in-service training to prepare teachers for curriculum changes is one of the major challenges affecting the successful implementation of the curriculum. ${ }^{10,11}$ Although teachers were invited to attend workshops, teachers found them to be ineffective in providing them with the knowledge they needed to understand new content. There was not enough time allocated for training for facilitators to address and clarify all the changes adequately, and attend to individual teacher's challenges. Although they did not learn much from the DBE workshops, the five teachers said that these workshops provided a platform for teachers to speak out and ask for support and guidance from teachers outside their own schools. They were less interested in the workshop content itself; instead, the gathering rendered informal networks of support.

Findings revealed that facilitators for the workshops lacked adequate understanding of the new content in Accounting. As such, teachers got an opportunity to consult other teachers in the cluster on issues pertaining to content delivery that may need further clarification. It is worth noting that supervising curriculum implementation through provision of advisory services and regular monitoring assist in fostering the professional development of teachers. ${ }^{14}$ Such services provide teachers with appropriate information for their professional advancement whilst promoting good pedagogical practices. Nevertheless, findings revealed that advisory support was not offered to Accounting teachers in the teaching of new content in schools. Teachers indicated that subject advisors seldom provided follow-up visits to schools after teachers had attended workshops and to monitor implementation of curriculum changes.

\section{Conclusion}

Stemming from the continuous curriculum changes in Accounting and the need for teachers to implement the changes, this article sought to explore Accounting teachers' experiences of teaching the new Accounting curriculum in schools. The outcome of this study indicated that numerous factors were experienced by teachers as hindering their efforts to successfully implement curriculum changes in Accounting.

Whilst advisory support was important during the execution phase of frequent curriculum changes in Accounting, findings from this study indicated that regular supervision and continuous support was not offered to teachers by relevant DBE stakeholders. This frustrated teachers' attempts to get to grips with new content and ensure effective instruction.

Keeping in mind that Accounting is regarded as a subject that necessitates regular practice because of its practical nature, there was an outcry from teachers who participated in this study regarding the shortage of textbooks. Furthermore, textbooks were found deficient in guiding and supporting 
teachers with adequate activities and a relevant questioning style.

If the above obstacles can be addressed accordingly, it could lead to a better teaching experience for Accounting teachers as well as a more successful implementation of curriculum changes. For instance, if on-going support was provided by subject advisors in KwaZulu-Natal schools to assist teachers with challenging topics and teaching strategies, teachers would gain more confidence in their skills, and this would enhance their teaching greatly.

Drawing from the findings presented, making textbooks available to teachers in addition to the prescribed one is recommended to assist in enhancing authentic teaching and learning and in seeing concepts from different perspectives. The study also recommended that heads of departments should be fully trained on curriculum changes in their subjects to be able to provide guidance, supervision and other support services to teachers under their leadership.

This study is, however, limited in that the findings only represent the experiences of five teachers from five schools in one district. Therefore, results cannot be generalised beyond this sample. There is also potential for further research to shed light on the broader scope of experiences of teaching the new Accounting curriculum, which could yield diverse results. Subsequent research could be a quantitative study with a large number of Accounting teachers in several districts.

We thus conclude that the outcome of this study should inform research on the school teaching experience. Documenting the experience of teaching the Accounting changes can help the subject advisors and school management to understand the common factors that can affect the teaching of Accounting in the context of curriculum change, and to find possible ways to navigate them.

\section{Acknowledgements Competing interests}

The authors declare that they have no financial or personal relationships that may have inappropriately influenced them in writing this article.

\section{Authors' contributions}

J.C.N. and N.V.S. conceptualised the study. N.V.S. collected and analysed data with the assistance of both J.C.N. and M.O. J.C.N. wrote the first draft and M.O. conducted the literature review. All authors read and approved the final version of the manuscript.

\section{Ethical considerations}

Permission to conduct this study was granted by the University of KwaZulu-Natal (REF. HSS/1262/01BM), the Department of Education, the school principals as well as the participating Accounting teachers. Other ethical procedures, procedures, which informed consent, confidentiality and anonymity, and voluntary participation were explained to the participants and adhered to throughout the duration of the study. All participants were kept anonymous by giving them pseudonyms (Zama, Beauty, Brian, Zuzeka and Senzo).

\section{Funding information}

This research received no specific grant from any funding agency in the public, commercial, or not-for-profit sectors.

\section{Data availability}

Data sharing is not applicable to this article as no new data were created or analysed in this study.

\section{Disclaimer}

The views and opinions expressed in this article are those of the authors and do not necessarily reflect the official policy or position of any affiliated agency of the authors.

\section{References}

1. Koopman K. A curriculum of inclusivity: Towards a lived body and a lived experience curriculum in South Africa. Indo Pac J Phenomenol. 2018;18(2):1-12. https://doi.org/10/1080/20797222.2018.1536360

2. Mbatha MG. Teachers' experiences of implementing the curriculum and assessment policy statement (Caps) in grade 10 in selected schools at Ndwedwe in Durban. Durban: University of South Africa; 2016.

3. Barac K, Du Plessis L. Teaching pervasive skills to South African accounting students. S Afr Business Rev. 2014;18(1):53-79. https://doi.org/10.25159/1998$8125 / 5645$

4. Myers LP. Knowledge structures and their relevance for teaching and learning in introductory financial accounting. S Afr J Account Res. 2016;30(1):79-95. https:// doi.org/10.1080/10291954.2015.1099215

5. Eskola A. Good learning in accounting: Phenomenographic study on experiences of Finnish higher education students. Vol. 101. Jyväskylä Studies in Business and Economics; 2011.

6. Ngwenya JC. Formative assessment in accounting: Exploring teachers' understanding and practices [PhD thesis]. Durban: University of KwaZulu-Natal; 2013.

7. Umalusi. What's in the CAPS package? A comparative study of the National Curriculum Statement (NCS) and the Curriculum and Assessment Policy Statement (CAPS): FET Phase Accounting, South Africa. Tshwane: Government Printers; 2014.

8. Kwarteng JT. Quality in senior high school accounting education in Ghana [PhD dissertation]. Ghana: University of South Africa; 2013.

9. Letshwele MG. Improving grade 10 accounting teachers' competencies in the Ekurhuleni District of the Gauteng province [Master's thesis]. Johannesburg: University of South Africa; 2014.

10. Makunja G. Challenges facing teachers in implementing competence-based curriculum in Tanzania: The case of community secondary schools in Morogoro municipality. Int J Educ Soc Sci. 2016;3(5):30-37.

11. Okoth TA. Challenges of implementing a top-down curriculum innovation in English language teaching: Perspectives of form III English language teachers in Kenya. J Educ Pract. 2016;7(3):169-177.

12. Shilling T. Opportunities and challenges of curriculum mapping implementation in one school setting: Considerations for school leaders. J Curric Instruct. 2013;7(2):20-37. https://doi.org/10.3776/joci.2013.v7n2p20-37

13. Syomwene A. Factors affecting teachers' implementation of curriculum reforms and educational policies in schools: The Kenyan experience. J Educ Pract. 2013;4(22):80-86

14. Bekoe SO, Eshun I. Curriculum feuding and implementation challenges: The case of senior high school (SHS) social studies in Ghana. J Educ Pract. 2013;4(5):39-45.

15. Njoku DI, Njoku NC. Challenges to effective implementation of Christian religious studies curriculum: A study of secondary school pupils in Ebonyi state of Nigeria. J Educ Pract. 2015;18(6):23-89.

16. Thomson F, Washington HL. Critical thinking skills and teaching accounting: A comparative study. J Finance Account. 2015;19:1-18.

17. Sabola BC. Managing the implementation of a school curriculum in Malawi: Challenges and policy implications. Textile Int J Manag. 2017;3(2):1-12. https:// doi.org/10.21522/TIJMG.2015.03.02.Art011 
18. Erasmus LJ, Fourie H. Inclusive accountancy programmes in South African higher education: A revised teaching approach. Account Educ. 2018:27(5):495-512. https://doi.org/10.1080/09639284.2018.1507828

19. Rogan JM, Grayson DJ. Towards a theory of curriculum implementation with particular reference to science education in developing countries. Int J Sci Educ. 2003;25(10):1171-1204. https://doi.org/10.1080/09500690210145819

20. Fullan MG. The new meaning of educational change. 4th ed. London: Teachers College Press; 2007.

21. Cohen L, Manion L, Morrison K. Research methods in education. 8th ed. London Routledge; 2018.

22. Farrugia B. Write a scientific paper: Sampling in qualitative research. Early Hum Dev. 2019;133:69-71. https://doi.org/10.1016/j.earlhumdev.2019.03.016
23. Creswell JW, Clark VLP. Designing and conducting mixed methods research Thousand Oaks, CA: Sage; 2017.

24. Creswell, JW. Research design: Qualitative, quantitative and mixed methods approaches. 4th ed. Thousand Oaks, CA: Sage; 2014.

25. Ajani OA. Need for in-service professional development of teachers to improve students' academic performance in sub-Saharan Africa. Arts Soc Sci J. 2018;9(2):1-7.

26. Ferreira JG. Teaching life sciences to English second language learners: What do teachers do? S Afr J Educ. 2011;31(1):102-113. https://doi.org/10.15700/saje. v31n1a409

27. Ngwenya JC, Maistry SM. Teaching and assessment in accounting: An exploration of teachers' experiences in a rural KwaZulu-Natal School. J Soc Sci. 2017;33(1):21-30. https://doi.org/10.1080/09718923.2012.11893083 